\title{
Research and Application of Modern Information Technology in the Forest Plant Protection Machinery
}

\author{
Lairong Chen ${ }^{1}$, Qingchun $\mathrm{Wang}^{1}$, and Ronghua $\mathrm{Ji}^{2,3, *}$ \\ ${ }^{1}$ School of Technology, Beijing Forestry University, Beijing, P.R. China 100083 \\ ${ }^{2}$ College of Electric and Information Engineering, China Agriculture University, Beijing, \\ P.R. China 100083 \\ ${ }^{3}$ College of Engineering, China Agriculture University, Beijing, P.R. China, 100083, \\ Tel.: +86-010-62336221 \\ jessic1212@cau.edu.cn
}

\begin{abstract}
Forest pests and diseases is very important to forest because it not only restricts the development of forest, but also causes huge economic. Chemical pesticides control the pests and diseases effectively and pollute environment seriously. How to reduce the amount of pesticide is the research hotspot in the field of plant protection. Forest plant protection machinery is the most important way to spray chemical pesticides. With the development of various modern information technologies, forest plant protection machinery has entered the electronic age in developed country. There are many modern information technologies which are applied in forest plant protection machinery, such as database, 3S technology, and sensor technology and so on. In this paper, a large number of relevant scientific literatures have been analyzed and compared in order to summarize application of modern information technology in the forest plant protection machinery. As the wide forest range, forest plant protection machinery should base mainly on large-scale spraying. $3 \mathrm{~S}$ technologies, database technology, computer control technology and a variety of detection techniques should be effectively combined together and applied in forest plant protection machinery in order to meet environmental safety requirements and improve the efficiency.
\end{abstract}

Keywords: Forest, Plant Protection Machinery, Pests and diseases, Information Technology.

\section{Introduction}

Forest is essential resource for human being. Forest resources protection is comprehensive measure which includes the reasonable usage of soil, water and other renewable resources, improving the ecology environment, supporting social and economic sustainable development and so on. Precision forestry is purposed to meet the strategy of developing forestry production science, and realize the change forestry production from extensive to intensive. The basement of precision forestry is to collect all kinds of forestry information quickly and accurately, and detect and manage forest objects

\footnotetext{
* Corresponding author.
} 
effectively. However, forest object detection and management are bottleneck for precision forestry because forest objects are various and forest is a random variable environment. The forest pests and diseases become more and more serious for global warming, severe weather occurring frequently and inter-regional trade. Forest pests and diseases cause significant economic losses. Chemical pesticides are the important measure to control the forest pests and diseases. However, chemical pesticides also pollute environment seriously. To improve chemical pesticides utilization and reduce environmental pollution, forest plant protection machinery became one of important application directions of precision forestry.

Modern society is changed from industrialization to information. The global wave of information technology is droved by modern information technologies which are included computer technology, communication technology, network technology, multimedia technology, 3S technologies, and sensor technology and so on., modern information technologies are widely used modern forestry, especially for forest plant protection machinery.

In this paper, a large number of relevant scientific literatures have been analyzed and compared in order to summarize application of modern information technology in the forest plant protection machinery. The prospects of application and development of modern information technology in plant protection are discussed in this paper.

Modern information technology refers to access, process, transmit and utilize the information by computer and modern communications technology. Modern information technology is interdisciplinary science that includes computer technology, communications technology, multimedia technology, network technology and so on. The modern information technology develops rapidly and brings great economic and social benefits.

In order to find the development of modern information technology, the published academic papers are searched Engineering Index Database and Science Citation Database with the key words of modern information technology (such as databases, remote sensing, image processing and so on) for nearly 20 years (1990 2010). The results show that the research and application of all kinds of modern technology has become more popular since 1998, especially since 2004, the modern information technologies developed rapidly. Plant protection is taken as the joint keyword to search again. The research and applications of a variety of modern information technology in the plant protection began to increase from 1999. The trends are consistent with the development of modern information technology. It can be concluded that, with the rapid development of information technology, its application in plant protection has also been widespread concern. For example the number of published academic papers which are related with remote sensing is shown in Fig .1.

The pests and diseases are controlled effectively by chemical pesticides. The plant protection machinery is the machine to use chemical pesticides effectively. Plant protection machinery also protects the security of agriculture and forestry production. At the same time, it is a strong guarantee of protecting the ecological environment and natural resources. Intelligence, automation and green plant protection machineries become trends with the rapid development of modern information technology. How to reduce the amount of pesticide was the research hotspot in the field of plant protection machinery. A solid technical foundation is provided by the variety of modern information technology (such as $3 \mathrm{~S}$, control technology, image processing, pattern recognition, decision support systems and databases, etc.) for the realization of plant protection machinery. 


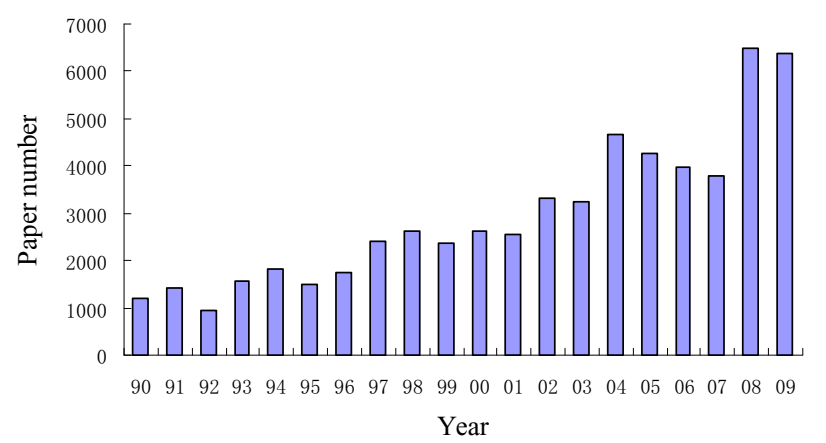

Fig. 1. The number of published academic papers related with remote sensing

\section{Research Overview}

There are many modern information technologies which are applied in the forest plant protection machinery, such as database, $3 \mathrm{~S}$ technology, and sensor technology and so on. The application of main modern information technologies are discussed as following.

\subsection{Database Technology}

Database technology is an important component of the modern information technology and the core of the data processing and information management system. Database technology can organize and store massive data efficiently for the information processing. Database technology can reduce the storage redundancy, safe sharing, and efficient processing. Database technology is widely used in pest management, especially in combination with expert system.

Data are the study foundation of the plant protection machinery. There are a variety of data which include observational data (such as meteorological data), historical data (such as beginning period, the disease index of forest pests and diseases in recent years and so on), empirical data (such as various of plant protection machinery application, operating conditions, etc.), experimental data (such as plant protection machinery control efficacy data, etc.) and a variety statistics data for pests and diseases and so on. It is important to effectively analysis and manage these data for plant protection machinery.

The management information system of ornamental plants diseases and pests was established [1].The system was included the ornamental diseases and pests database. Ornamental plants diseases and pests could be searched and distinguished in this system quickly and accurately. Forest disease remote consultation system was established [2]. The system was based on natural language understanding technology, database and network technology. The forest disease and insects could be remote diagnosed in this system. The inspection and forecast system of the forest plant diseases was build [3]. The developer tool and the structure design of database were introduced.

All relevant data could be effectively organized by database technology and formed independent data set for the application program. The strategic reference 
forest pest control could be provided by the independent data set. Pesticides could be sprayed accurately and effectively with the plant protection machinery.

A database set for intelligent plant protection machinery was build [4] which included the meteorological database, forest pests and diseases management database, plant protection machinery database, chemical application decision making dataset and plant protection machinery decision making dataset. The database set provided a case study showing how to prevent and control forestry pests and diseases effectively by using proper climate conditions, proper sciences and technologies. Database technology is mainly applied in pest management especially the expert system of plant protection. With the rapid development of plant protection and integration, database technology must be an important component of plant protection machinery.

\subsection{S Technology}

There are three parts of 3S technologies, which include Geographic Information Systems (GIS), Global Positioning System (GPS) and Remote Sensing (RS). Global Positioning System is global, all-day, continuous and real-time navigation, positioning system. Spatial location information is obtained in forest plant protection machinery in order to provide the spatial location of various types of sensors (such as CCD camera) and the delivery platform (such as vehicles, aircraft, etc.) rapidly. The forest plant protection machinery works according to the prescription map. The data, which is relative with geographical distribution of Earth's surface, is stored, managed, analyzed and described in Geographic Information System. The geographical location and attributes are associated together organically in GIS. At the same time, the spatial and attribute information are output accurately as a map according to user need. The spatial and attribute information are from a variety of sources in the forest plant protection system. The information is stored, managed, analyzed effectively, and mapped. GIS is a platform for forest plant protection system. Remote Sensing is the Earth observation technology with multi-platform, multi-band and high-resolution. The spectral information of natural target on Earth surface are obtained and processed by remote sensing in order to understand the natural world. Remote sensing is used to access the information of the environment and conditions of tree and update the GIS data timely in plant protection of forest.

Research was initiated on map-driven variable rate sprayers [5] using GIS or remote sensing information. A real time GPS-guided vehicle was the mapping of the spatial distribution and density of weeds combined with herbicide application with variable rate technology [6]. Through a learning community approach led by the Upper Midwest Aerospace Consortium [7], information was shared among scientists, agricultural producers, and data providers. SHI [8] discussed the controlling theory of the three kinds of variable rate spraying system and their advantages and disadvantages. The variable rate spraying system was based on GPS and GIS. Development of the SDSS for Medfly control in Israel, also known as MedCila, was described [9].The MedCila was integrated into a GIS environment. Working with the MedCila would enable the coordinator to make decisions for only around half of the plots. Cotton insect pests can be controlled early season using spatially variable insecticide applications [10]. Technology was developed for using GIS-based map. A spatially sensitive map could be developed that could drive a spatially variable insecticide 
application for the control of the insect pest. Farmers throughout the world are constantly searching for ways to maximize their returns. Remote Sensing, Geographic Information Systems, and Global Positioning Systems may provide technologies needed for farmers to maximize the economic and environmental benefits of precision farming. However, most farmers do not have the skills to utilize these technologies effectively. The positioning accuracy measurement of GPS in the forest was discussed [11]. It was put forward that the more concentrated positioning point, the higher positioning accuracy, otherwise the lower positioning accuracy.

One of the objectives of precision forest is to minimize the volume of herbicides that are applied to the plants through the use of site-specific plant management systems. RS, GIS and GPS may provide the technologies needed to maximize the economic and environmental benefits of precision forest. It is the inevitable trend that the plant protection machinery integrated with $3 \mathrm{~S}$ technologies for the complex forest object.

\subsection{Sensor Technology}

It is an importance problem for the development of intelligent plant protection machinery to detect the object effectively. A great variety of plant protection objects are changeable and complicate. It is an important bottleneck for the development of plant protection machinery to detect the plant protection object effectively. With the rapid development of various sensor technologies, the various sensors were widely used in various fields. The sensors, which are widely used in plant protection machinery, are optical sensor, ultrasonic sensors, and infrared sensors and so on.

Optical sensors can be used for recognition of plants and discrimination between plant species by utilizing image analysis methods and/or multi-spectra information. These types of sensors and processing methods have been developed intensively during recent years. Because the optical sensors have many advantages, it becomes the main sensor to apply in the intelligent plant protection machinery. The optical sensor-based plant detection systems [12] can detect all the green plants (weed and crop plants) and spray only on the plants. A machine vision guided precision band sprayer for small-plant foliar spraying [13] demonstrated a target deposition efficiency of 2.6-3.6 times that of a conventional sprayer, and the non-target deposition was reduced by 72-99\%.A precision spraying system called micro-spray was developed [14]. Micro-spray was designed for intra-row weed control. Herbicide is applied to the weed plants, only, and not to the crop plant and the soil. For highvalue crops, high-accuracy machine vision and control systems have been studied for outdoor field applications in California [15]. The smart sprayer, a local-vision-sensorbased precision chemical application system, was developed and tested [16]. An automatic computer vision-based approach for the detection and differential spraying of weeds in corn crops was described [17]. A weed recognition method based on Support Vector Machine was presented [18].

Intelligent Automatic Targeted tree sprayer with ultrasonic sensors can identify the distribution of trees (with tree or no tree) to do real time monitoring and make a decision whether to spray and how much to spray. Some work to verify the suitability of an ultrasonic sensor as a plants detector for a Mobile Robot was described [19]. An ultrasonic recognition system which was installed in the orchard 
crop spraying aircraft was developed by Taiwan Chung Hsing University. The Results showed that the proportion of pesticide savings of $57 \%$ compared with traditional spraying methods. Ultrasonic sensors to continuously detect the presence or absence of target trees; in regions where a sparse target is detected, spray output is modulated; when no target is detected, spraying is ceased.

The research challenge is to process the image timely and accurately for the application optical sensor in the plant protection machinery. The research hotspot is the image processing algorithm.

\section{Conclusion}

Forest plant protection is to protect and expand the forest resources. Forest plant protection machinery is an effective means to control forest diseases and insect pests. There are two major issues of plant protection machinery: how to improve efficiency of pesticides utilization and reduce the impact of pesticides to non-target organisms and the environment. With the development of various modern information technologies, forest plant protection machinery has entered the electronic age in developed country. The most important international plant protection machinery productions are Europe and the United States. Its products cover the world's major markets while its technology and equipment represent the highest level in today's world. As the wide forest range, forest plant protection machinery should base mainly on large-scale spraying. 3S technologies, database technology, computer control technology and a variety of detection techniques should be effectively combined together and applied in forest plant protection machinery in order to meet environmental safety requirements and improve the efficiency.

\section{Acknowledgements}

This program was supported by Beijing Forestry University Excellent Teacher Program (BLYX200907) and Beijing Excellent Talents Program (No. 20081D0500600147).

\section{References}

1. Cheng, G.: The Establishment of the Management Information System of Ornamental Plants Diseases and Pests in Qingdao. Journal of Shandong Forestry Science and Technology 5, 44-48 (2008) (in Chinese)

2. Wang, N., Zhang, Y., Wang, W.: Design and Realization of forest disease and insects Remote Consultation System based on natural language understanding. Journal of Natural Science of Heilongjiang University 6, 794-797 (2008) (in Chinese)

3. Sun, H.-m., Li, Y.-q., Li, X.-m.: The Design of the Inspection and Forecast System for the ForestPlant Diseases. Journal of Agricultural Mechanization Research 2, 226-227 (2004) (in Chinese) 
4. Zhang, H., Zheng, J., Zhou, H.: Specialized database technology for intelligent plant protection machinery. Transactions of the Chinese Society of Agricultural Engineering 1, 154-157 (2009) (in Chinese)

5. Rockwell, A.D., Ayers, P.D.: Variable rate sprayer development and evaluation. Applied Engineering in Agriculture 10, 327-333 (1994)

6. Nielsen, K.M., Andersen, P., Pedersen, T.S.: Control of an autonomous vehicle for registration of weed and crop in precision agriculture. In: IEEE Conference on Control Applications, Glasgow, Scotland, vol. 2, pp. 18-20 (2002)

7. Seelan, S.K., Laguette, S., Casady, G.M.: Remote sensing applications for precision agriculture: A learning community approach. Remote Sensing of Environment 12, 157-169 (2003)

8. Shi, W., Wang, X., Wang, X.: Variable Rate Spraying Technology on the Basis of GPS and GIS. Journal of Agricultural Mechanization Research 2, 19-21 (2007) (in Chinese)

9. Cohen, Y., Cohen, A., Hetzroni, A.: Spatial decision support system for Medfly control in citrus. Computers and Electronics in Agriculture 32, 107-117 (2008)

10. Mckinion, J.M., Jenkins, J.N., Willers, J.L.: Spatially variable insecticide applications for early season control of cotton insect pests. Computers and Electronics in Agriculture 67, 71-79 (2009)

11. Palmer, M.C.: Calculation of distance traveled by fishing vessels using GPS positional data: a theoretical evaluation of the sources of error. Fisheries Research 89, 57-64 (2008)

12. Shearer, S.A., Jones, P.T.: Selective application of post-emergence herbicides using photo electrics. Transactions of the ASAE 34, 1661-1666 (1991)

13. Giles, D.K., Slaughter, D.C.: Precision band sprayer with machine-vision guidance and adjustable yaw nozzles. Transactions of the ASAE 40, 29-36 (1997)

14. Lee, W.S., Slaughter, D.C., Giles, D.K.: Robotic weed control system for tomatoes. Precision Agriculture 1, 95-113 (1999)

15. Tian, L., Reid, J., Hummel, J.: Development of a precision sprayer for site-specific weed management. Transactions of the ASAE 42, 893-900 (1999)

16. Lei, T.: Development of a sensor-based precision herbicide application system. Computers and Electronics in Agriculture 36, 133-149 (2002)

17. Tellaeche, A., Artizzu, B., Xavier, P.: A vision-based method for weeds identification through the Bayesian decision theory. Pattern Recognition 41, 521-530 (2008)

18. Zhu, W., Zhu, X.: The application of support vector machine in weed classification. In: 2009 IEEE International Conference on Intelligent Computing and Intelligent Systems, vol. 4, pp. 532-536 (2009) (in Chinese)

19. Harper, N.L., McKerrow, P.J.: Recognition of plants with CTFM ultrasonic range data using a neural network. In: IEEE International Conference on Robotics and Automation, vol. 4, pp. 3244-3249 (1997) 